\title{
Development of General Aviation Cultural Tourism Resources Based
}

\author{
on "Internet+" \\ Liang zhisheng Zhangliang* \\ Guangzhou Civil Aviation College, Guangzhou, 510000 \\ *corresponding author: 25267764@QQ.com
}

Keywords: Development, Aviation, Tourism, Resources

Abstract: This paper analyzes the connotation of general aviation cultural tourism resources; constructs a general aviation culture tourism information service platform based on "Internet+"; proposes a general aviation cultural tourism development strategy based on "Internet+" thinking.

\section{Connotation of General Aviation Cultural Tourism Resources}

\section{(1) Connotation of General Aviation Cultural Tourism Resources}

Tourism is an important means to connect aviation resources and cultural spirit. In recent years, with the rapid development of China's economy and society, the concept of "tourism" has been highlighted, which has made the general aviation culture tourism more intension. General aviation cultural tourism is both an industrial culture and a popular culture. It is an important part of the advanced culture of socialism in the "new era".

(2) Analysis of General Aviation Cultural Tourism Resources

The general aviation cultural tourism resources are in fact one of the material representations of the general aviation industry to a more advanced stage. In recent years, with the support of the national policy level for the development of the general aviation industry, the prototypes and economies of the general aviation industry chain have been gradually formed in different economic regions. Looking at the current development of general aviation cultural activities can be summarized as the following types:

1) Tourist experience resources

The general aviation tourism experience products are static tourism products and can be used for public and high-end tourists. They include industrial tour, cultural experience, aerial sight-seeing and navigating tour routes [1].

2) Sports and leisure resources

The navigable sports and leisure resources are developed to meet the dreams of tourists, and they are challenging and irritating. They are mainly based on outdoor activities, divided into flight experience and navigating sports [1].

3) Navigate event products

Relying on the navigation facilities, it is also possible to host professional navigation sports competitions, professional summits, various types of air shows and other events, as well as events such as air weddings and aerial photography. Through the successful organization of the above activities, it can greatly enrich the regional atmosphere of navigation, quickly increase the popularity of the region, and drive related consumption, resulting in positive economic and social benefits for the region [1].

(3) Analysis of Factors Affecting the Development of General Aviation Cultural Tourism Resources

It is precisely because of the aviation characteristics of general aviation tourism that its 
development needs certain "special" conditions. The main factors include the main factors, basic service support factors, operational support factors, and external environmental factors.

The main factors mainly refer to participants in general aviation cultural tourism activities. Specifically, it includes two parts: the main body of demand and the main body of supply. Among them, the main demand includes the level of local market demand and the scale of external customer market. In layman's terms, it is a tourist. The travel motivation of general aviation tourists is to experience the pleasure of tourism with navigation as the core. It is imperative to conduct accurate analysis of the main demand and develop different navigation and cultural resources products for different groups of people. The supply main body refers to the main body that provides services for the operation and protection of the general aviation cultural tourism service, including navigation tour operators, fixed base operators, and general aviation pilots.

The basic service guarantee factor refers to the related systems that provide basic supporting facilities for the general aviation culture tourism, including the openness of the low-altitude airspace below 3,000 meters in China, the support of the air traffic control system, the functional perfection of the flight service station, and the type and quantity of general aviation aircraft.

Operational support factors refer to the factors affecting general aviation cultural tourism operations, including the support of industry types and quantities, traffic conditions from the tourist source to the destination, the improvement of the tour information support system, and the degree of online marketing promotion.

External environmental factors refer to policies, economics, natural environments and other factors. Specifically, it includes the government's policy orientation, economic development level, economic growth indicators, proportion of the tertiary industry, and natural environment factors.

\section{Based on "Internet+" general aviation culture tourism information}

\section{service platform}

(1) Platform construction concept under the "Internet + Tourism" model

With the development of the electronic information technology era, in order to improve their competitive advantages, more and more industries are attempting to accelerate business development through the overall solution of mobile informationization, and have played a major role in the development of traditional industries such as enterprise transformation, process optimization, and service enhancement. As a result, the "Internet + Tourism" development model has taken shape.

Tourism informationization is not only reflected in simple individual travel strategies, hotel and ticket reservation areas, but also in people's daily work, study and life [2]. The current mainstream website on tourism provides customers with comprehensive tourism information resources and experience channels. The "Internet + Tourism" development model has been fully formed. Based on the "Internet +" general aviation culture tourism information service platform is based on this status. The platform aims to provide a high level of general aviation cultural tourism information services, providing a one-stop "Internet + General Aviation Travel" solution for general aviation companies, scenic spots, governments, and tourists.

(2) Analysis of Platform Requirements

The navigation culture consumer groups are generally located in the middle of the society, and cultural consumption is based on the economic development of Chengdu. The higher the 
economic development in Chengdu, the better the residents' income and the higher the level of aviation culture consumption.

The level of education is generally higher. Navigation culture belongs to a kind of scientific and technological culture. Without certain cultural foundations and technological knowledge, it is difficult to appreciate the beauty of aviation culture. Therefore, the educational level of aviation culture consumers is generally higher than that of other tourism culture consumers.

The age structure of consumers is generally younger. The navigable culture is full of passion, dynamic, and is loved by young people. The navigation culture is full of adventure, bravery, pioneering and other elements. There are more outdoor activities and it is more suitable for men. Therefore, the proportion of male consumers is significantly higher than that of females.

The consumers of navigation culture are significantly affected by the living environment. The environment has a subtle influence on people's ideological consciousness. Living in an environment that is closely linked to aviation, it is naturally easier to cultivate "amateurs" of aviation culture, such as cities where aviation companies are concentrated, near large airports, air force garrisons, and coastal development. In regions and big cities, the proportion of aviation "fans" is significantly higher than in other regions.

From the perspective of demand, low-altitude tourism products are highly attractive to the current main forces of consumption after 80 and 90. This group places special emphasis on personalized travel experiences, likes to pursue fresh and exciting sensory experiences, and general aviation travel has a huge appeal.

Therefore, the establishment of the platform must meet the needs of consumer groups. The design concept of this platform is based on the combination of online and service and offline experience, using O2O's business operation model, development and operation management of general aviation cultural tourism projects, online marketing, and offline ticket inspection [3]. Gather general aviation culture tourism product development (includes industry information such as general aviation, tourism and real estate, and scenic spots, integrates data for later product development), customer maintenance (digital management of customer information, data analysis at a glance), marketing (combines with the Internet new media Cross-industry business cooperation, operation management (increase capacity control, save labor costs) as a large-scale low-altitude travel business APP.

1) Platform Operation Architecture

The basic operation mechanism of the "Internet+" general aviation cultural tourism information service platform is based on information technology such as internet of things, data warehousing, data mining, cloud computing, and SOA, and product development, service, marketing, and management are the main contents of the platform. The website, WAP webpage, and mobile client are the application media, providing users of the platform with reliable, practical, and necessary information services.

The characteristics of the platform are as follows: First, it establishes a safe and reliable forecasting and early warning mechanism through tourism companies and tourism regulatory agencies in conjunction with the meteorological, traffic, and other regulatory agencies to provide effective emergency response measures for emergencies; second, through big data integration and big data marketing, Cooperation with tourism resources operators to jointly design and develop general aviation cultural tourism products and product models for platform marketing. The third is to retrieve tourist activity information through Internet tourism resources, and to achieve accurate 
push of general aviation cultural tourism products for tourists.

2) Operation mechanism

The establishment of the "Internet + " general aviation culture tourism information service platform must ensure that enterprises can obtain market information accurately and timely, and at the same time meet the various information needs of tourists during the journey, through the establishment of market-based information between tourists and enterprises. The service platform realizes the good communication and interaction between tourism companies and tourists, and provides efficient and differentiated services according to the individual needs of customers, improves the overall service level, brings visitors a pleasant play experience, enhances the competitiveness of enterprises, and develops General aviation culture.

The core of platform construction and operation is to provide users with comprehensive tourism information and products. The platform provides two kinds of tourism services. One is a one-stop navigation and tourism culture product service. According to the Internet and big data marketing to obtain customer's consumer demand, develop general navigation and tourism cultural products, and for product design personalized transportation services, accommodation, catering services, scenic spots, packaged marketing model; the other is to provide a large amount of navigation and cultural tourism products, transportation services, food and beverage accommodation services, scenic services, customers can carry out DIY packaging.

From the front-end application of the platform to the management of important systems, technical support is provided to the back-end. Each port has to perform related functional work by different specific objects. The relationship between these objects is the partner of the platform. These partners include the government, general aviation associations, platform developers, general aviation cultural tourism operators, hotel catering service providers, transportation service providers, and scenic area service providers. The government and the association are responsible for the early stage propaganda, investment promotion, and industry linkage coordination of the lead platform construction. The platform developer will carry out the technical construction of the platform, including the design and development of the platform, the storage and maintenance of data, and the security of the network. The platform developer will also jointly develop tourism products with the general aviation cultural tourism operators.

\section{General aviation tourism development strategy based on "Internet}

\section{+" thinking}

Navigation tourism is a major development direction of the future tourism industry. The development of general aviation cultural tourism products should fully exploit the navigable cultural tourism resources, encourage more navigable operations and tourism activities, attach importance to the development of navigable tourism talents, and actively use advanced service concepts to improve the overall service quality; The improvement of the supporting services and occupying a favorable market position can effectively promote the sustainable development of navigation and cultural tourism.

The experience of navigating cultural tourism is very important. Using the rich and three-dimensional tourism resources in each region to create a complete experience from the process to the goal, it is conducive to building its own brand. At the government level, more consideration should be given to the integration of resources, and a series of policies to support 
local general aviation operating companies should be issued. Efforts should be made to use and use various types of navigation resources.

(1) Creating a good development environment

Navigation tourism is a combination of aviation elements and tourism industry, reorganization and redistribution of tourism resources. If local governments do not take active measures, they will certainly miss the golden opportunity for the development of navigation tourism. Local governments should take advantage of local unique navigational tourism resources and a large number of advantages and opportunities for the development of navigation tourism. Local governments should speed up the development of general aviation tourism development planning, and clarify the context and trends of development of general aviation tourism, and develop the development of navigation tourism. Create a good development environment.

(2) Make full use of navigation resources

Navigate tourism must highlight locality and culture. When carrying out the development of navigational cultural tourism products, we should combine the best known natural landscapes and the most attractive cultural and tourism activities in the region to integrate resources and fully tap the resources of general aviation tourism so as to develop more attractive Powerful and competitive navigation tourism products.

(3) Pay attention to nurturing tourism talents

Navigate tourism must attach importance to the development of general aviation tourism talents to enhance overall service quality. Develop a variety of general aviation tourism talents from tourism practitioners and general aviation service organizations, and strengthen the training of flight knowledge for navigating tourism practitioners, and strengthen the foreign language communication skills and international etiquette of relevant personnel so as to provide better tourism for tourists around the world. The service attaches great importance to the training of basic knowledge necessary for tour guides for general aviation, and fosters a high-quality, internationally navigable travel industry team as quickly as possible.

(4) Improve navigation services

Navigation and tourism agencies need to improve navigation and tourism support services. In terms of language, insurance, security introduction and service procedures, they all need to meet the standards of international general aviation. Only in this way can it occupy a favorable market position. From a long-term point of view, the development of navigable tourism should not only focus on the international certification of local service agencies, it is also necessary to dare to introduce advanced supporting services at home and abroad and attach importance to providing humanized services so as to be conducive to the formation of a good overall tourism image and truly "chasing and surpassing" services for the tourism industry.

\section{References}

[1]https://wenku.baidu.com/view/214d0b5b87c24028905fc32f.html

[2] Lin Xuyun. Research on transformation and upgrading of Conghua tourism service under the background of Internet + tourism [D]. Southwest Jiaotong University, 2016.

[3] Hui Yunyun. Research on evaluation of O2O e-commerce business mode 